\title{
Thermoelectric Performance of Micro/Nano-Structured Bismuth-Antimony-Telluride Bulk from Low Cost Mechanical Alloying
}

\author{
Z. Li ${ }^{1}$, G. L. Zhao ${ }^{*}$, P. Zhang ${ }^{2}$, S. Guo ${ }^{2}$, J. Tang ${ }^{3}$ \\ ${ }^{1}$ Department of Physics, Southern University and A \& M College, Baton Rouge, USA; ${ }^{2}$ Department of Mechanical Engineering, \\ Louisiana State University, Baton Rouge, USA; ${ }^{3}$ Department of Physics and Astronomy, University of Wyoming, Laramie, USA. \\ Email: *Guang-Lin_Zhao@subr.edu
}

Received October $6^{\text {th }}, 2012$; revised October $31^{\text {st }}, 2012$; accepted November $29^{\text {th }}, 2012$

\begin{abstract}
In this work, micro/nano-structured $\mathrm{Bi}_{0.5} \mathrm{Sb}_{1.5} \mathrm{Te}_{3}$ bulk thermoelectric materials were synthesized by mechanical alloying from elemental shots of $\mathrm{Bi}, \mathrm{Sb}$, and $\mathrm{Te}$. Cold pressing and subsequent heat treatments with hydrogen reduction were used to form bulk solid samples with good thermoelectric properties in the temperature range around $75^{\circ} \mathrm{C}$ to $100^{\circ} \mathrm{C}$. In comparison to crystal growth methods and chemical solution synthesis, the reported technique can be readily implemented for mass production with relatively low cost.
\end{abstract}

Keywords: Thermoelectric; $\mathrm{Bi}_{0.5} \mathrm{Sb}_{1.5} \mathrm{Te}_{3}$; Mechanical Alloying; Hydrogen Reduction

\section{Introduction}

Thermoelectric materials are important for power-generation devices that are designed to directly convert waste heat, solar thermal energy, geothermal energy, and other thermal energy into electrical energy [1], and play an important role in the current endeavor to develop renewable energy technologies for reducing the dependence on fossil fuels and cutting down greenhouse gas emissions. Novel thermoelectric materials can also be used in advanced solid-state refrigeration devices. The energy conversion efficiency of thermoelectric materials depends on the dimensionless thermoelectric figure of merit $(Z T)$ as

$$
Z T=\frac{S^{2} T}{\rho k}
$$

where $S$ is the Seebeck coefficient; $\rho$ is the electrical resistivity; $k$ is the thermal conductivity, and $T$ is the temperature. Good thermoelectric properties are often found in materials which are electrical conductors and thermal insulators with high Seebeck coefficient [2]. During the past decades, research efforts have been devoted to optimize the properties of $\mathrm{Bi}_{2} \mathrm{Te}_{3}$-based alloys, such as $\mathrm{Bi}_{2} \mathrm{Te}_{3}-\mathrm{Sb}_{2} \mathrm{Te}_{3}, \mathrm{Bi}_{2} \mathrm{Te}_{3}-\left(\mathrm{Bi}_{0.3} \mathrm{Sb}_{0.7}\right)_{2} \mathrm{Te}_{3}, \mathrm{Bi}_{2} \mathrm{Te}_{3}-\mathrm{Bi}_{2} \mathrm{Se}_{3}$, and related materials. Especially, since $1980 \mathrm{~s},\left(\mathrm{Bi}_{1-x} \mathrm{Sb}_{x}\right)_{2}$ $\mathrm{Te}_{3}$ (p-type) thermoelectric materials have intrigued the

${ }^{*}$ Corresponding author. attention of several research groups [3-5]. Different synthesis methods have been explored with different compositions for achieving a high thermoelectric performance $[2,6]$. The bismuth-antimony-telluride (Bi-Sb-Te) alloys are traditionally prepared by crystal growth methods such as Bridgman technology or Zone melting [7,8]. $\mathrm{Bi}-\mathrm{Sb}-\mathrm{Te}$ alloys have also been synthesized by direct chemical solution synthesis $[9,10]$, and by using mechanical alloying and spark plasma sintering [11]. The chemical solution synthesis is usually hard to produce large bulk thermoelectric materials for practical applications.

In this study, the mechanical alloying approach was further pursued, utilizing ball milling, cold pressing and heat treatment with an emphasis on hydrogen reduction in the synthesis of micro/nano-structured $\mathrm{Bi}_{0.5} \mathrm{Sb}_{1.5} \mathrm{Te}_{3}$ bulk alloy samples. Compared with other synthesis techniques as discussed above, this synthesis technique can be readily applied for large-scale production with relatively low cost, which provides a new opportunity for developing novel thermoelectrics applications. In this report, the detailed experimental procedures and operation parameters are included.

\section{Sample Preparation}

The $\mathrm{Bi}_{0.5} \mathrm{Sb}_{1.5} \mathrm{Te}_{3}$ alloy samples were fabricated from purified elemental shots of Bi (99.999\%), Sb (99.999\%), and Te (99.999\%), obtained from Sigma-Aldrich. Ap- 
propriate amounts of individual components were weighed with molar ratio of $\mathrm{Bi}: \mathrm{Sb}: \mathrm{Te}=1: 3: 6$. Ball milling (8000M Mixer/Mill, SPEX Certiprep, USA) is used to produce micro/nano powders, which were subjected to mechanical alloying. The vial and balls were made of hardened tool steel. To diminish the oxidization of the powders, two steps were implemented. The first was performing the ball milling for 40 hours in a glove box in an argon gas environment. The second was performing hydrogen reduction of the powders for 10 hours at $380^{\circ} \mathrm{C}$, after the ball milling. Then dry pressing dies (MTI Corporation) with inner diameters of $12.7 \mathrm{~mm}$ and $19.1 \mathrm{~mm}$ were used to cold press the powders into disks about 3 $\mathrm{mm}$ in thickness at a pressure of $12 \mathrm{MPa}$ and $18 \mathrm{MPa}$, respectively, for 1 hour. The bulk sample was then loaded into a custom made press cell, which has a total labor and materials cost less than one thousand USD (see Figure 1). The confinement pressure of the sample in cold condition in the press cell was about at about $18 \mathrm{MPa}$. The sample was made in a pressed condition during the heat treatment in a furnace with hydrogen environment. Similar to what was discussed in a previous publication on heat treatment [12], our repeated explorations showed that high heating rate could cause the sample to break. The inner portion and surface of the sample with temperature contrast could lead to stress distribution, which may cause the samples to crack. Therefore, a low heating rate with $2^{\circ} \mathrm{C} / \mathrm{min}$ was set for three-step continuous annealing: $280^{\circ} \mathrm{C}$ for $2 \mathrm{~h}, 330^{\circ} \mathrm{C}$ for $2 \mathrm{~h}$, and $380^{\circ} \mathrm{C}$ for $5 \mathrm{~h}$, successively. A photo image of a typical sample after annealing in hydrogen ambience is shown in Figure 2. The final bar samples were cut and burnished in a size of about $3 \times 4 \times 15 \mathrm{~mm}^{3}$ for thermoelectric properties characterizations.

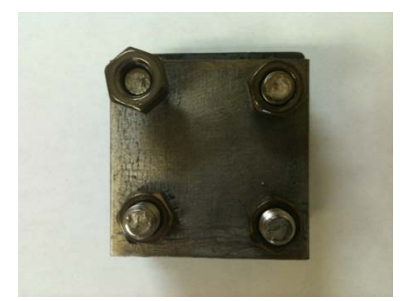

Figure 1. Press cell for making the sample in a pressed condition during the heat treatment.

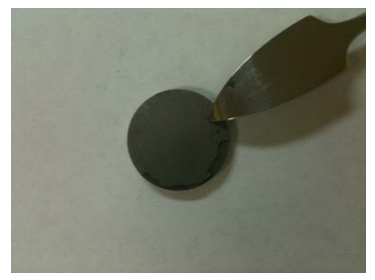

Figure 2. The disk-shaped sample obtained after annealing in hydrogen ambience.

\section{Measurement Results and Discussion}

X-ray diffraction (XRD) method (D8 Advance, Bruker AXS, Germany) using $\mathrm{Cu} \mathrm{K} \alpha$ radiation was used to characterize the sample crystal structures, scanned from $2 \theta=20^{\circ}$ to $80^{\circ}$. The XRD results of the powders after hydrogen reduction at $380^{\circ} \mathrm{C}$ and the annealed bulk sample were shown in Figures 3(a) and (b), respectively. Compared with the standard characteristic peaks of $\mathrm{Bi}_{0.5} \mathrm{Sb}_{1.5} \mathrm{Te}_{3}$ (vertical lines, PDF 49-1713, Jade, Materials Data Inc.), a single crystalline phase was identified, indicating that the alloy sample was successfully synthesized. A differential scanning calorimetry (DSC) (DSC 404 F1, Netzsch, Germany) was used in a temperature range from $25^{\circ} \mathrm{C}$ to $640^{\circ} \mathrm{C}$ to check the phase transitions of the powders. Figure 4 shows the DSC results of the powders. Only one DSC peak around $605^{\circ} \mathrm{C}$ is observed, which matches well with the melting point of $\mathrm{Bi}_{0.5} \mathrm{Sb}_{1.5} \mathrm{Te}_{3}$. The results verify that the powder product only consists of a single phase of $\mathrm{Bi}_{0.5} \mathrm{Sb}_{1.5} \mathrm{Te}_{3}$ compound.

Scanning electron microscopy (SEM) (JSM-6390, JEOL, USA) was applied for powders and bulk samples to examine the sample morphology and micro-structures.
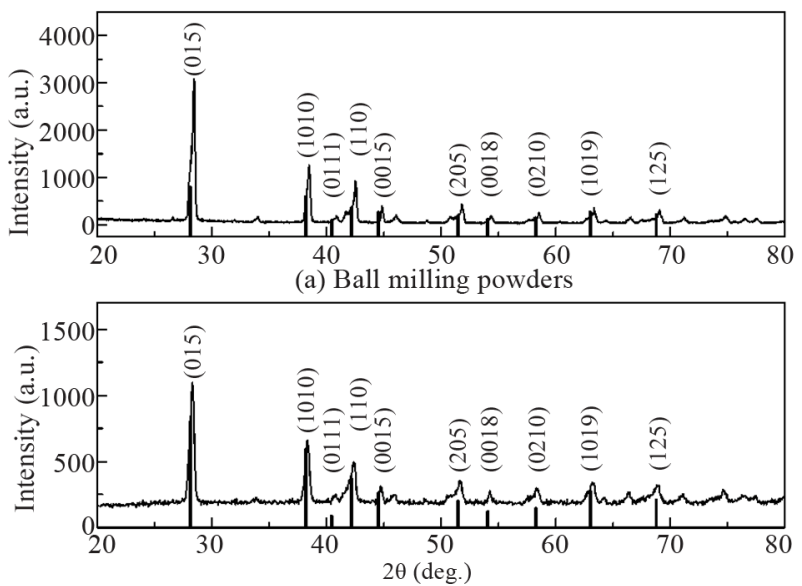

(b) Annealed alloyed bulk

Figure 3. XRD results of ball milling powders (a) and annealed alloy bulk (b).

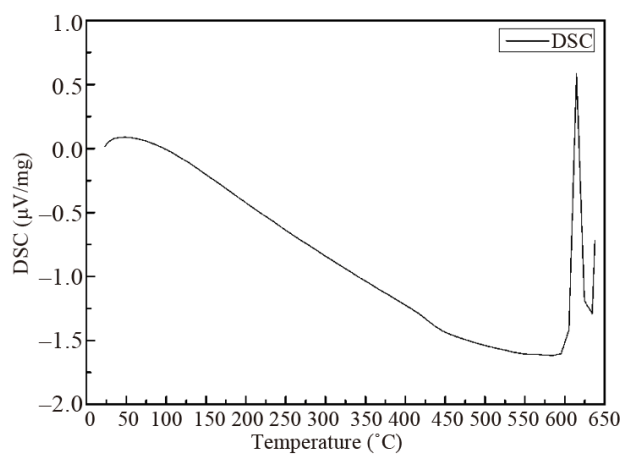

Figure 4. DSC results of the powders. 
The SEM images of the powders (Figure 5(A)) and the alloyed bulk after annealing (Figure 5(B)) show that some large alloy clusters have their sizes ranging up to more than $1 \mu \mathrm{m}$, with an average size of about $800 \mathrm{~nm}$. Some smaller nano-clusters (about $50-100 \mathrm{~nm}$ ) are distributed in between large alloy clusters. Meanwhile, alloy clusters in powders are distributed more chaotically than those in the sintered alloyed bulk. The in-plane SEM image of Figure 5(B) showed that through the heat treatment in the pressed condition, the mechanically assisted reaction and thermal energy can make alloy clusters to align more preferably along the orientation perpendicular to the compression direction. Heremans et al. [13] and Kim et al. [14] discussed that the embedded nanoparticles can play as nano-inclusions, which scatter mid-to long-wavelength phonons more effectively, whereas atomic-scale defects in host materials scatter the Brillouinzone-edge phonons more effectively. In our sample, the smaller nano-clusters may play as nano-inclusions in the matrix of larger alloy clusters. Satyala et al. discussed that the additional interfaces can also scatter electrons and deteriorate charge carrier transport [15]. Thus, the crystalline sizes in the material should be large in comparison to the charge carrier mean free path, which is more than $300 \mathrm{~nm}$ around room temperature for $\mathrm{Bi}_{0.5} \mathrm{Sb}_{1.5} \mathrm{Te}_{3}$ [16], that is comparable to the sizes of the large alloy clusters in our sample.
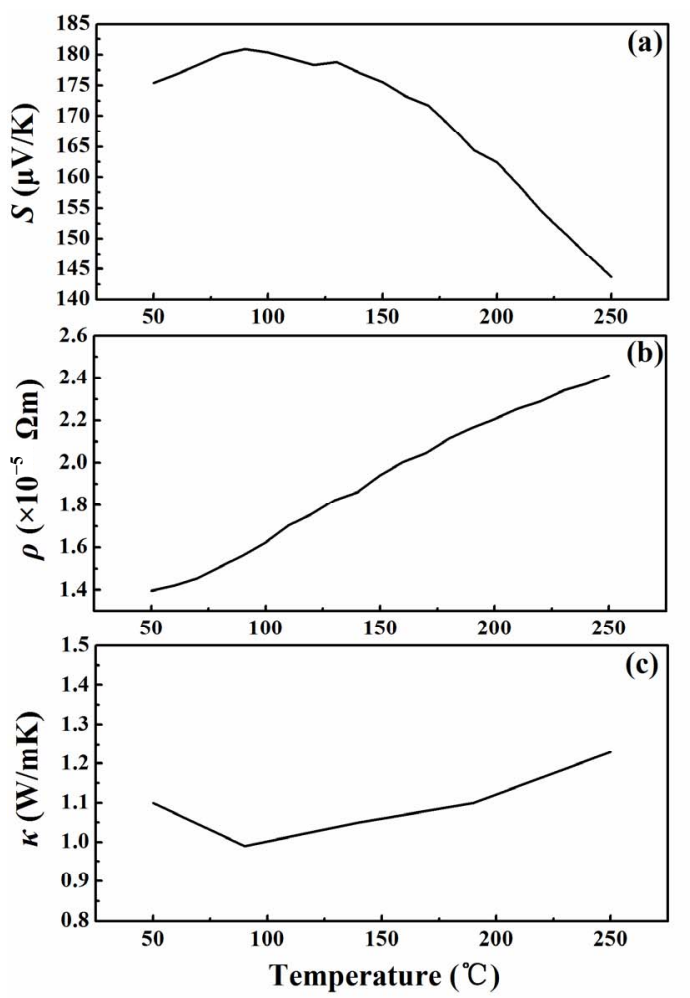

The Seebeck coefficient and electrical resistivity of the bar samples were characterized by using a ZEM-3 equipment (Ulvac-Riko, Inc., Japan) for the base temperature $50^{\circ} \mathrm{C}$ to $250^{\circ} \mathrm{C}$. Disk samples (diameter of 12.7 $\mathrm{mm}$ ) were loaded onto Flashline 5000 Thermal Properties Analyzer (Anter Coroperation, USA) for thermal conductivity measurement. Figure 6 presents the meas-

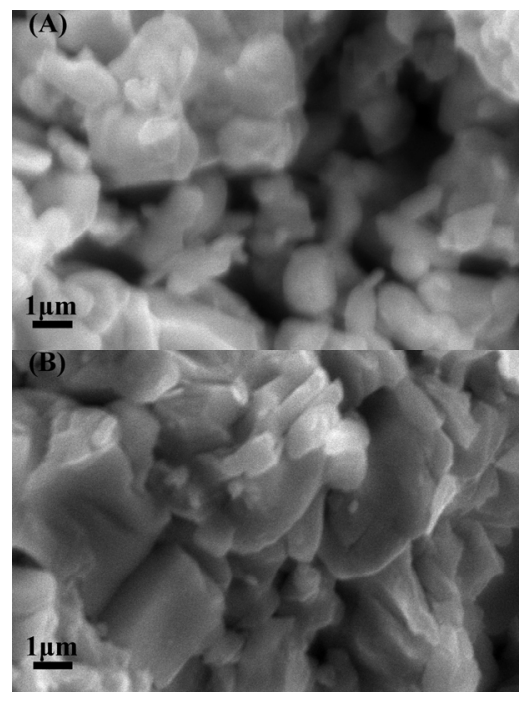

Figure 5. SEM images of ball milling powders (A) and annealed alloy bulk (B).
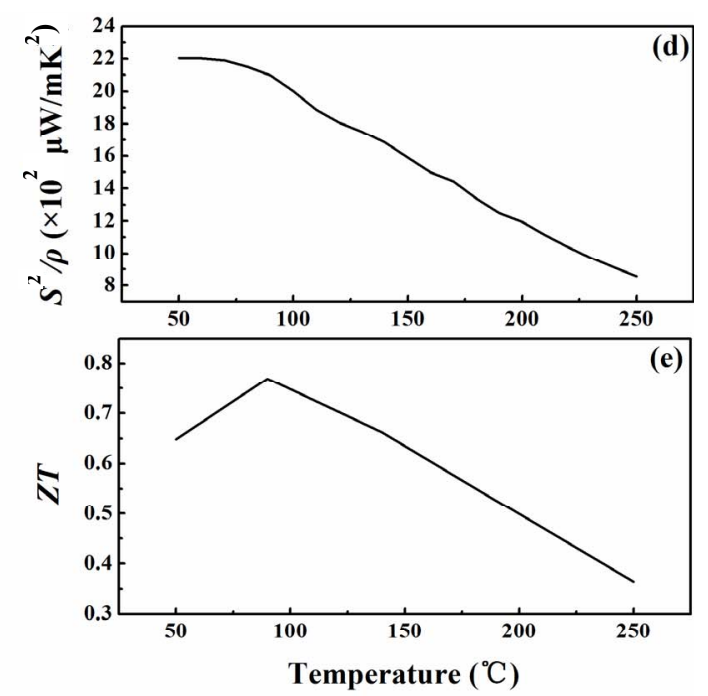

Figure 6. Temperature dependence of thermoelectric properties of bulk $\mathrm{Bi}_{0.5} \mathrm{Sb}_{1.5} \mathrm{Te}_{3}$ alloy sample. (a) Seebeck coefficient; (b) Electrical resistivity; (c) Thermal conductivity; (d) Power factor; and (e) The thermoelectric figure of merit. 
ured thermoelectric properties of the bulk $\mathrm{Bi}_{0.5} \mathrm{Sb}_{1.5} \mathrm{Te}_{3}$ alloy sample. The measured thermoelectric Seebeck coefficient of the sample is presented in Figure 6(a). When temperature increased from $50^{\circ} \mathrm{C}$ to $90^{\circ} \mathrm{C}$, the Seebeck coefficient increased from 175 to the maximum value of $181 \mu \mathrm{V} / \mathrm{K}$ at $90^{\circ} \mathrm{C}$. As the temperature increased above $90^{\circ} \mathrm{C}$ to $250^{\circ} \mathrm{C}$, the Seebeck coefficient decreased to 144 $\mu \mathrm{V} / \mathrm{K}$.

Another electronic transport property of the samples is the temperature dependence of electrical resistivity (Figure 6(b)). The electric resistivity of bulk sample shows a metallic behavior, instead of a semiconducting one, due to mechanical alloying. The resistivity significantly rises as temperature increases. Nevertheless, the resistivity is below $1.6 \times 10^{-5} \Omega \mathrm{m}$ from room temperature to $100^{\circ} \mathrm{C}$, which is among the desired performances of the best thermoelectric materials. ${ }^{2}$ In comparison, the resistivity of the sintered sample without hydrogen reduction in heat treatment is between $6.3 \times 10^{-5} \Omega \mathrm{m}$ and $7.2 \times 10^{-5}$ $\Omega \mathrm{m}$ from $50^{\circ} \mathrm{C}$ to $250^{\circ} \mathrm{C}$, that are much higher than the results shown in Figure 6(b). Therefore, this relatively high performance of the electronic transport properties of the samples is attributed to the utilizations of hydrogen reduction, which aim to reduce the effect of oxidation in material synthesis. The calculated power factor $\left(S^{2} / \rho\right)$ of the bulk sample is shown in Figure 6(d). It does not change much from $50^{\circ} \mathrm{C}$ to $75^{\circ} \mathrm{C}$, and decreases for temperatures higher than $75^{\circ} \mathrm{C}$. The thermal conductivity $\kappa$ of the disk-type bulk sample was measured by a laserflash apparatus (Netzsch Instruments, Inc., USA). The laser-flash apparatus measured the thermal diffusivity and heat capacity at the same time. With the mass density of the sample, the thermal conductivity can be calculated using an equation as

$$
k=\alpha d c_{p}
$$

where $\alpha$ is thermal diffusivity; $c_{p}$ is heat capacity; and $d$ is the mass density. The measured mass density of the sample is $6.648 \mathrm{~g} / \mathrm{cm}^{3}$, which is about $96.7 \%$ of the theoretical mass density of $6.878 \mathrm{~g} / \mathrm{cm}[3,17]$. Figure 6(c) shows the measured thermal conductivity of the bulk samples made from the powders, which is lower than those reported of crystalline ingots. The reduction of thermal conductivity is attributed to the large phonon scattering at the interfaces in the micro/nano-structured samples [6]. The lowest thermal conductivity is around $90^{\circ} \mathrm{C}$ with an approximate value of $0.98 \mathrm{~W} / \mathrm{mK}$. Figure 6(e) shows the temperature dependence of the figure-ofmerit $(Z T)$ of the bulk thermoelectric sample. The peak $Z T$ of the bulk sample made from powders through the $\mathrm{H}$-reduction is about 0.8 near the temperature of $80^{\circ} \mathrm{C}$. It is among the desired value of the high performance of thermoelectric material families of $\mathrm{Bi}_{2} \mathrm{Te}_{3}$ alloys, for ap- plications around $75^{\circ} \mathrm{C}$ to $100^{\circ} \mathrm{C}[18,19]$.

\section{Conclusion}

In this paper, the detailed procedures and experimental parameters are presented for a new synthesis route of micro/nano-structured $\mathrm{Bi}_{0.5} \mathrm{Sb}_{1.5} \mathrm{Te}_{3}$ bulk thermoelectric materials. A low cost fabrication route of using mechaincal alloying of elemental shots, cold press, and subsequent heat treatments with hydrogen reduction is presented. The experimentally measured thermoelectric properties, including Seebeck coefficient, electrical resistivity, power factor, thermal conductivity, and figure of merit have shown that the fabricated bulk thermoelectric material exhibits high performance for thermoelectric applications in the temperature range around $75^{\circ} \mathrm{C}$ to $100^{\circ} \mathrm{C}$. In comparison to crystal growth methods and chemical solution synthesis, this synthesis technique opens a new vista for mass production with relatively low cost.

\section{Acknowledgements}

The authors wish to thank Drs. Stephen Akwaboa, Edwin Walke, Weihua Wang, and Scott Wicker for their assistances in using some measurement instruments. The work is funded in part by the National Science Foundation (Award No. CBET-0754821), the Air Force Office of Scientific Research (Award No. FA9550-09-1-0367), and NSF LASIGMA Project (Award No. EPS-1003897, NSF92010-15-RII-SUBR).

\section{REFERENCES}

[1] K. Matsubara, "Development of a High Efficient Thermoelectric Stack for a Waste Exhaust Heat Recovery of Vehicle," IEEE Proceedings of 21 st International Conference on Thermoelectrics, ICT'02, Long Beach, 25 August-29 August 2002, pp. 418-423. doi:10.1109/ICT.2002.1190350

[2] D. M. Rowe, "Thermoelectrics Handbook-Macro to Nano," CRC-Taylor \& Francis, Boca Raton, 2006.

[3] A. Krost, "Landolt-Bornstein (New Series), Group III: Crystal and Solid State Physics," Springer-Verlag, Berlin, 1983, p. 234.

[4] K. Stecker, M. Stordeur and H. T. Langhammer, "Verbindungshalbleiter," Akademische Verlagsgesellschaft Geest u. Portig, Leipzig, 1986, p. 304.

[5] P. Kao, "Growth and Analysis of Thermoelectric Material $\left(\mathrm{Bi}_{1-\mathrm{x}} \mathrm{Sb}_{\mathrm{x}}\right)_{2} \mathrm{Te}_{3}$ Crystal," M.S. Thesis, National Dong Hwa University, Taiwan, 2000.

[6] M. Stordeur, M. Stölzer, H. Sobotta and V. Riede, "Investigation of the Valence Band Structure of Thermoelectric $\left(\mathrm{Bi}_{1-\mathrm{x}} \mathrm{Sb}_{\mathrm{x}}\right)_{2} \mathrm{Te}_{3}$ Single Crystals," Physica Status Solidi $B$, Vol. 150, No. 1, 1988, pp. 165-176. 
doi: $10.1002 /$ pssb.2221500120

[7] D. B. Hyun, T. S. Oh, J. S. Hwang, J. D. Shim and N. V. Kolomoets, "Electrical and Thermoelectric Properties of $90 \% \mathrm{Bi}_{2} \mathrm{Te}_{3}-5 \% \mathrm{Sb}_{2} \mathrm{Te}_{3}-5 \% \mathrm{Sb}_{2} \mathrm{Se}_{3}$ Single Crystals Doped with $\mathrm{SbI}_{3}, "$ Scripta Materialia, Vol. 40, No. 1, 1998, pp. 49-56. doi:10.1016/S1359-6462(98)00393-5

[8] O. Yamashita, S. Tomiyoshi and K. Makita, "Bismuth Telluride Compounds with High Thermoelectric Figures of Merit," Journal of Applied Physics, Vol. 93, No. 1, 2003, p. 368. doi:10.1063/1.1525400

[9] Y. Zhao and C. Burda, "Chemical Synthesis of $\mathrm{Bi}_{0.5} \mathrm{Sb}_{1.5} \mathrm{Te}_{3}$ Nanocrystals and Their Surface Oxidation Properties," Applied Materials and Interfaces, Vol. 1, No. 6, 2009, pp. 1259-1263. doi:10.1021/am900148d

[10] M. E. Anderson, S. S. N. Bharadwaya and R. E. Schaak, "Modified Polyol Synthesis of Bulk-Scale Nanostructured Bismuth Antimony Telluride," Journal of Materials Chemistry, Vol. 20, No. 38, 2010, pp. 8362-8367. doi:10.1039/c0jm01424a

[11] C. Chen, D. W. Liu, B. P. Zhang and J. F. Li, "Enhanced Thermoelectric Properties Obtained by Compositional Optimization in p-Type $\mathrm{Bi}_{\mathrm{x}} \mathrm{Sb}_{2-\mathrm{x}} \mathrm{Te}_{3}$ Fabricated by Mechanical Alloying and Spark Plasma Sintering," Journal of Electronic Materials, Vol. 40, No. 5, 2011, pp. 942947. doi:10.1007/s11664-010-1463-2

[12] Z. Qi, C. Zhou, H. Gao, S. Liu and C. Wang, "The Impact of Heat Treatment Process on Austenite Grain Size in Axle Steel," Locomotive \& Rolling Stock Technology, Vol. 4, 1984, p. 1.

[13] J. P. Heremans, C. M. Thrush and D. T. Morelli, "Thermopower Enhancement in PbTe with $\mathrm{Pb}$ Precipitates," Journal of Applied Physics, Vol. 98, No. 6, 2005, Article ID: 063703. doi:10.1063/1.2037209
[14] W. Kim, J. Zide, A. Gossard, D. Klenov, S. Stemmer, A. Shakouri and A. Majumdar, "Thermal Conductivity Reduction and Thermoelectric Figure of Merit Increase by Embedding Nanoparticles in Crystalline Semiconductors," Physical Review Letters, Vol. 96, No. 4, 2006, Article ID: 045901. doi:10.1103/PhysRevLett.96.045901

[15] N. Satyala and D. Vashaee, "The Effect of Crystallite Size on Thermoelectric Properties of Bulk Nanostructured Magnesium Silicide $\left(\mathrm{Mg}_{2} \mathrm{Si}\right)$ Compounds," Applied Physics Letters, Vol. 100, No. 7, 2012, Article ID: 073107. doi:10.1063/1.3684615

[16] I. H. Kim, "Electronic Transport Properties of the FlashEvaporated p-Type $\mathrm{Bi}_{0.5} \mathrm{Sb}_{1.5} \mathrm{Te}_{3}$ Thermoelectric Thin Films," Material Letters, Vol. 44, No. 2, 2000, pp. 75-79. doi:10.1016/S0167-577X(00)00005-7

[17] C.-J. Liu, G.-J. Liu, Y.-L. Liu and L.-R. Chen, "Enhanced Thermoelectric Performance of Compacted $\mathrm{Bi}_{0.5} \mathrm{Sb}_{1.5} \mathrm{Te}_{3}$ Nanoplatelets with Low Thermal Conductivity," Journal of Material Research, Vol. 26, No. 15, 2011, pp. 17551761. doi:10.1557/jmr.2011.158

[18] M. Ashida, T. Hamachiyo, K. Hasezaki, H. Matsunoshita and Z. Horita, "Effect of High Pressure Torsion on Crystal Orientation to Improve the Thermoelectric Property of a $\mathrm{Bi}_{2} \mathrm{Te}_{3}$-Based Thermoelectric Semiconductor," Advanced Materials Research, Vol. 89-91, 2010, pp. 41-46. doi:10.4028/www.scientific.net/AMR.89-91.41

[19] J. S. Son, M. K. Choi, M. K. Han, K. Park, J. Y. Kim, S. J. Lim, M. Oh, Y. Kuk, C. Park, S.-J. Kim and T. Hyeon, "n-Type Nanostructured Thermoelectric Materials Prepared from Chemically Synthesized Ultrathin $\mathrm{Bi}_{2} \mathrm{Te}_{3} \mathrm{Na}-$ noplates," Nano Letters, Vol. 12, No. 2, 2012, pp. 640647. doi:10.1021/n1203389x 